\title{
Stability and Complexity Analysis of a Dual-Channel Closed-Loop Supply Chain with Delayed Decision under Government Intervention
}

\author{
Daoming Dai ${ }^{1}$, Fengshan $\mathrm{Si}^{1, *}$ and Jing Wang ${ }^{2}$ \\ 1 School of Management Science and Engineering, Anhui University of Finance and Economics, \\ Bengbu 233030, China; ddmaufe@126.com \\ 2 Faculty of Science, Bengbu University, Bengbu 233030, China; crystalstella@126.com \\ * Correspondence: 120081671@aufe.edu.cn or sifs2007@126.com
}

Received: 21 September 2017; Accepted: 21 October 2017; Published: 26 October 2017

\begin{abstract}
This paper constructs a continuous dual-channel closed-loop supply chain (DCLSC) model with delayed decision under government intervention. The existence conditions of the local stability of the equilibrium point are discussed. We analyze the influence of delay parameters, the adjustment speed of wholesale price, recovery rate of waste products, direct price, carbon quota subsidy, and carbon tax on the stability and complexity of model by using bifurcation diagram, entropy diagram, attractor, and time series diagram and so on. Besides, the delay feedback control method is adopted to control the unstable or chaotic system effectively. The main conclusions of this paper show that the variables mentioned above must be within a reasonable range. Otherwise, the model will lose stability or enter chaos. The government can effectively adjust manufacturers' profit through carbon tax and carbon quota subsidy, and encourage manufacturers to reduce carbon emissions and increase the remanufacturing of waste products.
\end{abstract}

Keywords: dual-channel closed-loop supply chain; government intervention; delayed decision; entropy; stability; complexity

\section{Introduction}

The rapid development of the Internet has increased people's shopping choices, and nowadays online shopping and physical stores coexist, so this paper studies closed-loop supply chain (CLSC) problems against the background of dual-channel retail availability. This is in line with social reality.

At the same time, with the rapid economic development and the improvement of people's living standards, energy consumption and the replacement of products have been accelerated. The product waste has brought great pressure on the environment. Therefore, energy-saving and emissions-reduction have become topics of common concern to the people around the world. In this paper, we pay attention to the recycling and remanufacturing of waste products, reusing as many waste products as possible, thus saving resources and reducing environmental pollution. Moreover, it is necessary to encourage enterprises to recycle and remanufacture products and reduce carbon emissions through government intervention. Recycling means that the waste products provided by the retailer to a manufacturer only appear as raw materials in the manufacturer's manufacturing process. In this paper, the products obtained from waste products are called remanufactured products. Remanufacturing is an industrial process that turns waste products into "like-new" products [1]. Typically, remanufactured products are as good as new products in quality because of manufacturers adopt special process technology. Reducing carbon emissions indicates that enterprises reduce emissions by improving production technology and increasing products remanufacturing under the intervention of carbon tax and carbon quota subsidy measures. Therefore, we propose that CLSC 
is conducive to promoting the reuse of resources. In addition, both the product sales and the recycling of waste products are closely related to the price, so manufacturer and retailer must set reasonable prices to maximize profits. This has good practical significance.

In this context, many scholars have discussed carbon emissions and government interference in dual-channel supply chains, closed-loop supply chains and multi-echelon supply chains. They have obtained a lot of valuable research results. In addition, some scholars have studied the dynamic behavior of CLSC, focusing on the impact of parameters on the dynamic behaviors of the system.

Much research has been performed on carbon emissions in dual-channel supply chains and closed-loop supply chains. Ji et al. [2] studied the carbon emission reduction behaviors of members in a dual-channel supply chain which includes cap-and-trade regulation and consumers' low-carbon preference. Research suggests that manufacturers can increase profits by opening up direct channels when the low carbon sensitivity of consumers meets certain conditions. Xu et al. [3] analyzed the influence of carbon emissions on hybrid CLSC structures and dedicated CLSC structures. A set of integrated mixed integer linear programming models to quantify the effects is developed and the impact of carbon emissions policies and market factors on CLSC structure is compared. The results show that the impact of scale effect and product income on customer demand is less than the total cost and total emissions under considering market conditions. Zheng et al. [4] built a CLSC logistics integration optimization model, and proposed a CLSC logistics integration management method, which can reduce carbon emissions and increase the value of the supply chain. Fahimnia et al. [5] established a unified optimization model for a CLSC. They assessed the impact of positive and reverse supply chains on carbon footprint. The study found that cost and environmental changes affect the range of carbon pricing. Bazan et al. [6] proposed two-echelon supply chain model which consists of one manufacturer and one retailer. They focus on three key environmental issues: the energy used in production, GHG (Greenhouse Gas) emissions and the amount of remanufactured product. Qi et al. [7] explored a two-echelon supply chain consisting of one supplier and two retailers under carbon cap regulation. They pay attention to the price decision process of supply chain members, and find out the best wholesale price and retail price. The research shows that the combination of wholesale price and retail price with transfer payment is the best price decision. In addition, the study found that a reasonable carbon emission limit can effectively reduce carbon emissions. Tao et al. [8] studied the equilibrium problem of CLSC networks including manufacturer, retailer, demand market and recovery in a multi-period planning horizon. A network equilibrium model is established under the condition of the carbon emission constraint of periodic and global. They analyze the influence of two kinds of constraints on the network equilibrium of CLSC.

Normally, the government encourages enterprises to undertake energy-saving and emissionreduction, waste recycling and remanufacturing actions through carbon taxes and carbon quota subsidies. Therefore, scholars have studied the effects of government intervention in CLSC. Sheu et al. [9] analyzed the influence of government financial intervention on green supply chain competition in the three-stage game model. Their studies showed that the government should adopt green tax and subsidy measures to ensure that the green products produced by enterprises make profits. Wang et al. [10] discussed the government's carbon emission tax policy in the three-stage Stackelberg game model with a decentralized supply chain and the two-stage Stackelberg game model with a centralized supply chain. The results show that centralized supply chain is more advantageous to enterprises and government than decentralized supply chain. Fareeduddin et al. [11] proposed a CLSC design and logistics operation optimization model based on carbon regulation policy. The impacts of different policies on emission reduction costs are analyzed. The findings can help policymakers predict the impact of normative policies on total carbon emissions in the supply chain operations. He et al. [12] discussed the impact of free riding behavior of consumers and government taxes on carbon emissions in CLSC is analyzed. The results show that manufacturer can derive economic benefits from consumer free riding behavior, but the total carbon emissions in the whole supply chain are also increasing. In addition, the government can reduce the free rider 
behavior and total carbon emissions through carbon tax Li et al. [13] studied the impact of carbon subsidy on remanufacturing closed-loop supply chain (RCLSC). They discuss the profits and the carbon emission quantities in forward supply chain and RCLSC with the carbon subsidy. The studies show that when the price of the recovery meets certain conditions, the government can implement carbon subsidies, and the amount of subsidies should be within a reasonable range. Ma et al. [14] explored the influence of consumption subsidy on dual-channel closed-loop supply chain (DCLSC for short). Research shows that all consumers who buy new products benefit from the government's consumption subsidies. Zhao et al. [15] developed a decision model considering the effects of consumer preferences on remanufactured products and government subsidies. Remanufacturing pricing and the sharing of subsidies between the manufacturers and consumers are discussed. The study found that if manufacturers share a certain proportion of government subsidies, they can gain more profits when the market expands. Mitra et al. [16] analyzed a two-period model which production and sale of new products and remanufactured products, respectively. They focus on the incentive role of government subsidies for remanufacturers. The results show that reasonable sharing of subsidies can increase the profits of manufacturers and remanufacturers, and promote the recovery and remanufacturing of products. Yang et al. [17] established three game models of green supply chain with government intervention under the fuzzy uncertainty of production cost and consumer demand. The influence of channel leaders and government intervention on product price, green level and expected profit is analyzed. The results show that retailers have more advantages as the leader of game model when government intervention is too strong. Heydari et al. [18] analyzed the operation decisions of two-echelon reverse supply chains consisting of one manufacturer and one retailer. They propose quantity discounts, increasing fee contracts and different incentives provided by the government to coordinate supply chains. The study found that gross profit was improved in the case of supply chain coordination.

Whether it is energy-saving emission-reduction measures or the government's intervention policies, as well as the price of recycling of waste products have to fluctuate in a certain range, otherwise it will backfire. Therefore, scholars have also studied the game behavior of supply chains. Xie et al. [19] discussed the game behaviors of a duopoly color TV recovery market consisting of two recyclers and one processor. It is found that the abrupt change of the adjustment coefficient of the decision variable leads to chaos in the system. The system will be confused and the regional stability of the system will be reduced when the parameters are beneficial to manufacturers, consumers and the environment. Ma et al. [20] studied the game behaviors of products recycling in a CLSC with one manufacturer and one retailer, such as bifurcations and chaos. The research shows that the increase of retailer status is easy to lead the system into chaos. Guo et al. [21] established a CLSC pricing game model consisting of a manufacturer and a retailer. They explore the complex dynamical behaviors of the system and analyze the effects of parameters on system stability and complexity. The research conclusions can provide reference for prices decision of manufacturer and retailer. Zhou et al. [22] studied the three-echelon CLSC consisting of one supplier, one manufacturer and one retailer. They focus on the effects of the factors on the system dynamic characteristics. The results show that the higher yield can improve the dynamic performance when the unit step response as input.

To sum up, we find that scholars mainly discuss carbon emissions, carbon tax and government subsidies in dual-channel supply chains or the CLSC. In addition, the influence of supply chain parameters on the system is analyzed by scholars. However, we are more concerned about the following aspects: (1) the game behaviors of product sales and recycling in DCLSC are studied; (2) manufacturers sell new products and remanufactured products through direct channel and retailer channel, respectively; (3) the government encourages manufacturers to recycle and remanufacture waste products by using carbon quota subsidies and carbon tax policy simultaneously; (4) manufacturers and retailers adopt postponement strategies when making price decisions; (5) the influence of parameters on the stability and complexity is analyzed based on entropy theory and nonlinear dynamics theory; (6) the chaotic system is effectively controlled by using the method of delayed feedback control. 
The main contributions of this paper are as follows: first, we construct a dual-channel closed-loop supply chain model with time delay based on government intervention, and discuss the price decision problems of manufacturers and retailers. Second, the influence of various decision critical parameters on the dynamic behaviors of supply chain system are analyzed, such as bifurcation, chaos and entropy. The ranges of parameters to maintain the stability of the system are also given. Third, we explore the effective incentive measures of government to manufacturer and the control method of chaotic system. Fourth, the research results of this paper can provide valuable reference for manufacturer, retailer and government decision-making.

The rest of the paper is structured as follows: Section 2 establishes a continuous DCLSC model with delayed decision under government intervention. The local stability of equilibrium point of model is discussed in this section. Section 3 analyzes the influence of parameters on the stability and complexity of the DCLSC through numerical simulation. The chaotic system is successfully controlled by the delayed feedback control method in Section 4 . Section 5 presents a summary of this paper and prospects for future research.

\section{The Model}

We structure a DCLSC model consisting of one manufacturer and one retailer. The retailer is responsible for recycling waste products and then sells them to the manufacturer. The manufacturer produces new products by using new materials and uses waste products for remanufacturing. In order to help consumers to distinguish new products from remanufactured products, the manufacturer sells them through a direct channel and the retailer channel, respectively. Consumers can buy products through these two channels according to their own needs.

In general, manufacturer uses special manufacturing processes to make remanufactured products as good as new products in quality and performance. Therefore, the products sold through the two channels are homogeneous, that is to say, they are substitutes. This leads to an inevitable price competition between channels. In addition, in order to reduce environmental pollution, the government forces the manufacturer to improve the emission-reduction level by imposing a carbon tax. Meanwhile, the government encourages the manufacturer to recycle and reuse waste products through a carbon quota subsidy. The carbon quota subsidy obtained by the manufacturer is positively related to the ratio of the quantity of remanufactured products to the quantity of new products.

The DCLSC structure is shown in Figure 1. The meanings of the different parameters are described in Table 1.

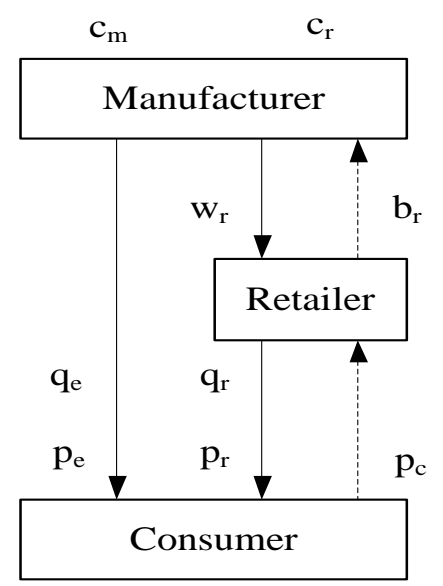

Figure 1. Dual-channel closed-loop supply chain structure diagram. 
Table 1. Parameter description.

\begin{tabular}{cc}
\hline Symbol & Descriptions \\
\hline$c_{m}$ & Production cost of unit new product \\
$c_{r}$ & Production cost of unit remanufactured product \\
$w_{r}$ & Wholesale price provided by the manufacturer to the retailer \\
$b_{r}$ & Recovery price of unit product for manufacturer \\
$q_{e}$ & Market demand for direct channel \\
$q_{r}$ & Market demand for retailer channel \\
$q$ & Supply quantity of waste products \\
$\theta$ & Recovery rate of waste products \\
$\gamma$ & The ratio of remanufactured products and new products \\
$p_{e}$ & Price of unit product in direct channel (direct price for short) \\
$p_{r}$ & Price of unit product in retailer channel (retail price for short) \\
$p_{c}$ & Recycling price of unit waste product \\
$s$ & The quantity of waste products voluntarily provided by consumers \\
$k$ & Sensitive coefficient of recovery price for consumer \\
$e_{i}$ & Carbon emissions of unit product $(i=p, r ; p=$ production, $r$ remanufactured) \\
$c_{e}$ & Carbon tax of unit carbon emission \\
$q_{f}$ & Basic carbon quota subsidy provided by government for manufacturer \\
$\pi_{r}$ & Retailer's profit \\
$\pi_{m}$ & Manufacturer's profit \\
$\tau_{r}$ & Decision delay parameter of retail price \\
$\tau_{w}$ & Decision delay parameter of recovery price \\
$\tau_{c}$ &
\end{tabular}

Assumptions of the general model:

(i) The cost of a unit of new product is higher than that of a unit of remanufactured product, $c_{m}>c_{r}$.

(ii) Recovery rate of waste products $\theta \in[0,1]$. The retailer is responsible for the inspection of waste products to ensure compliance with the remanufacturing standards. $\theta=0$ indicates that there are no qualified waste products for remanufacturing in the market, while $\theta=1$ is an ideal situation, which means that all the waste products can be used for remanufacturing.

(iii) To ensure the retailer can make a profit, let $p_{r}>w_{r}$ and $b_{r}>p_{c}$.

(iv) Carbon emissions per unit of new product are higher than those of a unit of remanufactured product, $e_{p}>e_{r}$.

(v) We do not consider the sale cost and other costs of the two channels.

(vi) All products recycled by the retailer are resold to the manufacturer for remanufacturing.

The function of consumers to provide waste products is as follows:

$$
q=s+k p_{c}
$$

Equation (1) shows that the supply of waste products comes from two sources. On the one hand, consumers voluntarily provide waste products. On the other hand, consumers sell waste products to retailers according to the recycling price. Obviously, the higher the recycling price, the more consumers will be willing to sell waste products. The sensitivity of consumers to recycling prices is denoted by $k$.

The product demand functions of direct channel and retailer channel are given by:

$$
\begin{gathered}
q_{e}=a-b p_{e}+c p_{r} \\
q_{r}=\theta q-b p_{r}+c p_{e}
\end{gathered}
$$

where $a>0$ and $\theta q>0$ are the market capacities of new products and remanufactured products respectively. $b>0$ is the price elasticity coefficient, $c>0$ is the cross price sensitivity coefficient. $b>c$ represents that the price has more impact on its own demand than cross price. Equation (2) implies 
that the demand for new products in the direct channel is negatively related to the direct price, while it is positively related to the retail price. Equation (3) has a similar meanings. That is to say, lowering the retail price or raising the direct price the will increase the market demand of the retailer channel and vice versa.

The carbon emissions of new products and remanufactured products are $q_{e} e_{p}$ and $q_{r} e_{r}$ respectively, so the total carbon tax paid by the manufacturer is:

$$
c_{e}\left[q_{e} e_{p}+q_{r} e_{r}\right]
$$

With reference to Hypothesis (iv), we can draw the following conclusions from Equation (4) when the other conditions are fixed. Manufacturers can effectively reduce the total carbon tax by increasing the remanufacturing of waste products. At the same time, manufacturers can also reduce carbon emissions per unit product (including new and remanufactured products) by improving the manufacturing technology. In addition, the government can directly affect the manufacturer's profit through per unit carbon emission tax revenue.

The government provides a carbon quota subsidy for manufacturers $\gamma q_{f}$. The amount of carbon quota subsidy obtained by a manufacturer depends on the ratio of remanufactured products and new products, that is $\gamma=q_{r} / q_{e}$. This can motivate manufacturers to be more engaged in remanufacturing waste products.

With the above analysis, we formulate the profit functions for manufacturer and retailer:

$$
\begin{gathered}
\pi_{r}=\left(p_{r}-w_{r}+b_{r}-p_{c}\right) q_{r} \\
\pi_{m}=\left(p_{e}-c_{m}\right) q_{e}+\left(w_{r}-c_{r}-b_{r}\right) q_{r}-c_{e}\left[q_{e} e_{p}+q_{r} e_{r}-\gamma q_{f}\right]
\end{gathered}
$$

For brevity, we assume that the quantity of new products is equal to the remanufactured products, i.e., $\gamma=1$. This shows that manufacturers can obtain the basic carbon quota subsidy provided by the government.

We consider the Nash game in the price game market. Because of the complexity and uncertainty of environmental constraints, it is difficult for manufacturers and retailers to make decisions under completely rational conditions. Therefore, we assume that manufacturer and retailer make decisions in the context of bounded rationality (limited information processing capacity, self-discipline, knowledge, information, and experience). However, the Nash equilibrium is an optimal strategy based on complete rational hypothesis and obtained by rigorous logic operation, so it is difficult for the manufacturer and retailer in a bounded rationality scenario to achieve Nash equilibrium in the short run. The purpose of their decisions is to converge to the Nash equilibrium. It is also a process in which manufacturer and retailer learn from each other and adjust their strategies [23].

The decision process is as follows: the manufacturer determines the wholesale price and the retailer determines the retail price and recycle price simultaneously according to their own knowledge and experience. Then, the manufacturer and retailer adjust their strategies on the basis of the decisions made by the other player and the maximization of their own utility. In the course of the repeated game of strategy interaction and behavior learning, the strategy combination of manufacturer and retailer is close to the Nash equilibrium. In this state, manufacturer and retailer have made optimal decisions, and none of them are willing to take the initiative to make strategic changes.

As manufacturer and retailer have incomplete market information in the game process, so they refer to marginal profit when making decisions. From Equations (1)-(3), (5) and (6), the marginal profits for manufacturer and retailer with respect to $p_{r}, p_{c}$ and $w_{r}$ are given by:

$$
\left\{\begin{array}{l}
\frac{\partial \pi_{r}\left(p_{r}, p_{c}, w_{r}\right)}{\partial p_{r}}=\theta q+c p_{e}-b p_{r}-b\left(b_{r}-p_{c}+p_{r}-w_{r}\right) \\
\frac{\partial \pi_{r}\left(p_{r}, p_{c}, w_{r}\right)}{\partial p_{c}}=-\theta q-c p_{e}+b p_{r}+k \theta\left(b_{r}-p_{c}+p_{r}-w_{r}\right) \\
\frac{\partial \pi_{m}\left(p_{r}, p_{c}, w_{r}\right)}{\partial w_{r}}=c p_{e}-b p_{r}+\theta q
\end{array}\right.
$$


If $\partial \pi_{r} / \partial p_{r}>0$ and $\partial \pi_{r} / \partial p_{c}>0$, the retailer raises the retail price and recovery price, and vice versa. If $\partial \pi_{m} / \partial w_{r}>0$, the manufacturer raises the wholesale price, and vice versa, so the dynamic price adjustment process is as follows:

$$
\left\{\begin{array}{l}
\dot{p}_{i}(t)=\alpha_{i}\left(p_{i}\right) \frac{\partial \pi_{r}\left(p_{r}, p_{c}, w_{r}\right)}{\partial p_{i}}, i=r, c \\
\dot{w}_{r}(t)=\alpha_{w}\left(w_{r}\right) \frac{\partial \pi_{m}\left(p_{r}, p_{c}, w_{r}\right)}{\partial w_{r}}
\end{array}\right.
$$

where $\alpha_{i}\left(p_{i}\right)$ represents the influence factor of marginal profit on retail price and recovery price, $\alpha_{w}\left(w_{r}\right)$ indicates the influence factor of marginal profit on the wholesale price. We assume that $\alpha_{i}\left(p_{i}\right)$ and $\alpha_{w}\left(w_{r}\right)$ are linear functions. Namely:

$$
\left\{\begin{array}{l}
\alpha_{i}\left(p_{i}\right)=v_{i} p_{i}, i=r, c \\
\alpha_{w}\left(w_{r}\right)=v_{w} w_{r}
\end{array}\right.
$$

where $v_{i}>0$ represents the adjustment speeds of retail price and recovery price, $v_{w}>0$ indicates the adjustment speed of the wholesale price.

Substituting Equations (7) and (9) into Equation (8), we obtain the price game model of DCLSC as follows:

$$
\left\{\begin{array}{l}
\dot{p_{r}}=v_{r} p_{r}\left(\theta\left(s+k p_{c}\right)+c p_{e}-b p_{r}-b\left(b_{r}-p_{c}+p_{r}-w_{r}\right)\right) \\
\dot{p}_{c}=v_{c} p_{c}\left(-\theta\left(s+k p_{c}\right)-c p_{e}+b p_{r}+k \theta\left(b_{r}-p_{c}+p_{r}-w_{r}\right)\right) \\
\dot{w_{r}}=v_{w} w_{r}\left(c p_{e}-b p_{r}+\theta\left(s+k p_{c}\right)\right)
\end{array}\right.
$$

Manufacturer and retailer are decision makers with bounded rationality. They not only consider the current price, but also refer to historical prices to make sure that the decisions made are more accurate. The delay parameter is $\tau_{w}$ when the manufacturer sets the wholesale price, and the delay parameter for retail price and recovery price is $\tau_{r}$ and $\tau_{c}$ respectively. Therefore, the dynamic game process with delay strategy can be translated into:

$$
\left\{\begin{array}{l}
\dot{p}_{i}(t)=v_{i} p_{i} \frac{\partial \pi_{r}\left(p_{r}^{d}, p_{c}^{d}, w_{r}^{d}\right)}{\left.\partial p_{i}\right)}, i=r, c \\
\dot{w}_{r}(t)=v_{w} w_{r} \frac{\partial \pi_{m}\left(p_{r}^{d}, p_{c}^{d}, w_{r}^{d}\right)}{\partial w_{r}}
\end{array}\right.
$$

where:

$p_{r}^{d}=w_{r}^{\prime} p_{r}(t)+\left(1-w_{r}^{\prime}\right) p_{r}\left(t-\tau_{r}\right), p_{c}^{d}=w_{c}^{\prime} p_{c}(t)+\left(1-w_{c}^{\prime}\right) p_{c}\left(t-\tau_{c}\right)$, $w_{r}^{d}=w_{w}^{\prime} w_{r}(t)+\left(1-w_{w}^{\prime}\right) w_{r}\left(t-\tau_{w}\right)$.

The superscript $d$ means postponement decision. $0 \leq w_{r}^{\prime}, w_{c}^{\prime}, w_{w}^{\prime} \leq 1$ represent the weight of the current prices when the manufacturer and retailer make decisions. Since current prices are difficult to obtain accurately and timely, we assume that manufacturer and retailer only consider historical prices to make decisions. That means $w_{r}^{\prime}=w_{c}^{\prime}=w_{w}^{\prime}=0$ and $\tau_{r}, \tau_{c}, \tau_{w}>0$. Therefore, the stability and complexity of the system are discussed when $\tau_{i}>0, i=r, c, w$ in this paper.

Based on above description and discussion, Equation (10) can be converted to:

$$
\left\{\begin{array}{l}
\dot{p_{r}}=v_{r} p_{r}\left[\theta s+(\theta k+b) p_{c}\left(t-\tau_{c}\right)+c p_{e}-2 b p_{r}\left(t-\tau_{r}\right)-b b_{r}+b w_{r}\left(t-\tau_{w}\right)\right] \\
\dot{p_{c}}=v_{c} p_{c}\left[-\theta s-2 \theta k p_{c}\left(t-\tau_{c}\right)-c p_{e}+(b+k \theta) p_{r}\left(t-\tau_{r}\right)+k \theta b_{r}-k \theta w w_{r}\left(t-\tau_{w}\right)\right] \\
\dot{w_{r}}=v_{w} w_{r}\left[\theta s+\theta k p_{c}\left(t-\tau_{c}\right)+c p_{e}-b p_{r}\left(t-\tau_{r}\right)\right]
\end{array}\right.
$$

Let us assume the equilibrium point of Equation (12) is $E\left(p_{r}^{*}, p_{c}^{*}, w_{r}^{*}\right)$. In other words, the system will tend to the equilibrium point after game. Based on the Hopf bifurcation theorem in [24], we have the following conclusion (the proof is in Appendix A): 
Theorem 1. The equilibrium point $E\left(p_{r}^{*}, p_{c}^{*}, w_{r}^{*}\right)$ of Equation (12) is asymptotically stable for $\tau \in\left[0, \tau_{0}\right)$ and it is unstable for $\tau>\tau_{0}$. Equation (12) has a Hopf bifurcation at $\tau=\tau_{0}$. Where $\tau=\tau_{r}=\tau_{c}+\tau_{w}$, $\tau_{0}$ indicates the critical value of the delay to ensure the stability of the system.

\section{Numerical Simulation and Analysis}

Now we investigate the influence of several parameters on the stability and complexity of the system, and show the dynamic evolution process of the system from different perspectives. After assigning the parameters, it will be given the following system from Equation (12):

$$
\left\{\begin{array}{l}
\dot{p_{r}}=0.4 p_{r}\left[0.62+0.9 p_{c}\left(t-\tau_{c}\right)-p_{r}\left(t-\tau_{r}\right)+0.5 w_{r}\left(t-\tau_{w}\right)\right] \\
\dot{p_{c}}=0.5 p_{c}\left[-0.848-0.8 p_{c}\left(t-\tau_{c}\right)+0.9 p_{r}\left(t-\tau_{r}\right)-0.4 w_{r}\left(t-\tau_{w}\right)\right] \\
\dot{w_{r}}=0.6 w_{r}\left[0.92+0.4 p_{c}\left(t-\tau_{c}\right)-0.5 p_{r}\left(t-\tau_{r}\right)\right]
\end{array}\right.
$$

where $\tau_{r}=\tau_{c}+\tau_{w}=\tau$. We assume $\tau_{c}=\tau_{w}=\tau / 2$. By simple calculation, it is easy to obtain the equilibrium point of Equation (13) is $E(2.403,0.169,1.968)$. We can get $\omega_{0}=0.483, \tau_{0}=1.445$ by Equations (A8) and (A12). In addition, we can obtain $Q_{3}+Q_{4}=34.409 \neq 0$ and $z_{0}=-18.313<0$. On the basis of Theorem 1, the equilibrium point is asymptotically stable when $\tau \in[0,1.445)$ and it is unstable when $\tau>1$.445. It undergoes a Hopf bifurcation at $\tau=1.445$.

\subsection{The Influence of $\tau$ on the Stability and Complexity of Prices and Profits}

In this paper, we only consider $\tau>0$. Figure 2a shows the dynamic evolution behaviors of the system. We can find that Equation (13) changes from stability to instability with the increase of $\tau$, and finally it falls into chaos. The critical value of the system state change with respect to $\tau$ is 1.445. This conclusion is completely consistent with the above theoretical analysis. We further verify Theorem 1 by using the largest Lyapunov exponent (LLE for short) which measures the stability of system according to the relation between the exponent value and zero. The system is stable when exponent value is less than zero, while if exponent value is greater than zero, the system is unstable. Exponent value is equal to zero which indicates the system is losing stability. From Figure $2 b$ we can find out exponent value is equal to zero when $\tau=1.445$. On the left side of the critical value, the exponent value is less than zero, while on the other side is greater than zero. This is consistent with the meaning expressed in Figure 2a. We can also make clear that $\tau \in[0,1.445)$ is the stable region of the system (the system is also stable according to Theorem 1 when $\tau \in[0,1)$, we take $\tau \in[1,2]$ for the simulation effect). This tells us that manufacturer and retailer do not refer to historical prices as long as possible. In other words, the delay of the retail price can not exceed $\tau_{0}$, or the sum of the delay of recovery price and the delay of wholesale price can not exceed $\tau_{0}$. Otherwise, it will lead to price fluctuation and even enter chaos.

Complexity is another characteristic of the system. This paper uses Kolmogorov entropy to measure the complexity of the system. The rules for judging system complexity as follows: the system is stable when the entropy value is zero, and it maintains original complexity. Otherwise, if the entropy value is greater than zero, the system is unstable, and the complexity is increasing. On the basis of the above analysis, we can infer that the entropy value is equal to zero when $\tau<1.445$, and it is more than zero for $\tau>1$.445. The complexity of the system increases gradually with the increase of $\tau$. Figure $2 \mathrm{c}$ shows this property visually.

The effects of delay parameter on the profits of manufacturer and retailer are shown in Figure $2 \mathrm{~d}$. The profits of manufacturer and retailer are stable when $\tau<1.54$, while the profits will lose stability when $\tau>1.54$. The fluctuation trends of the profits are basically the same, but it will cause great losses to manufacturer and retailer. 


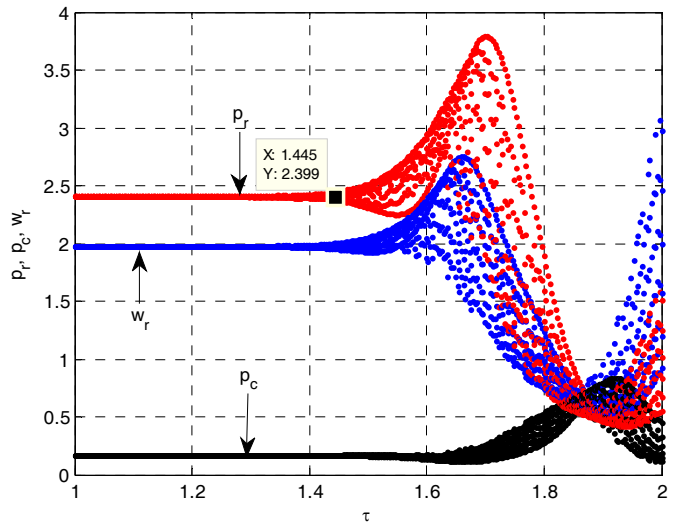

(a)



(c)

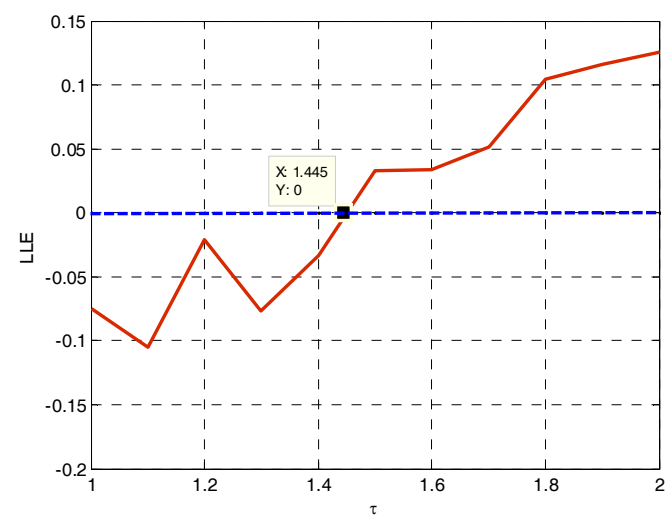

(b)

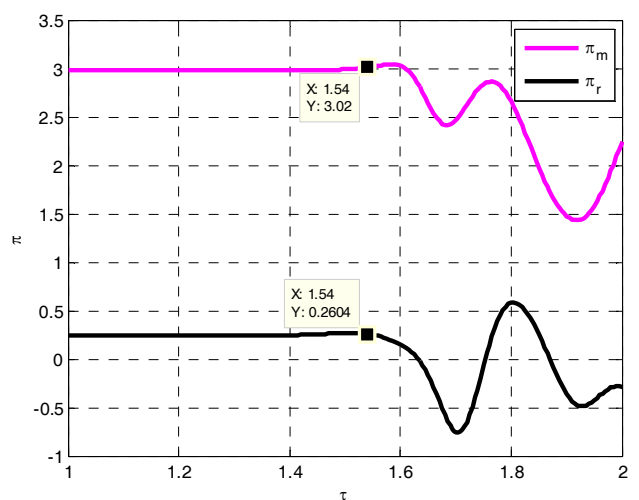

(d)

Figure 2. The impact of $\tau$ on the stability and complexity of Equation (13). (a) Bifurcation diagram; (b) the largest Lyapunov exponent diagram; (c) entropy diagram; and (d) profit change trends of the manufacturer and the retailer.

In summary, we can conclude that if the delay parameter goes beyond a certain range, the DCLSC game system will lose stability and become more complex, which is not good for manufacturer and retailer to make price decisions. This also shows that the price of a long time ago has no reference value to the current decision-making, but it is prone to decision-making errors. In addition, the fluctuation of the profits lags behind the instability of the prices.

The delay parameter $\tau$ increases from 1.2 to 2.18 , the system undergoes steady state, periodic state, quasi periodic state and chaotic state. Meanwhile, the system is also becoming more and more complex. Figure 3 shows the dynamic evolution process of the system from stable to chaos through attractor. It can be seen from Figure 3 a the system is stable, and the prices will tend to the equilibrium point after game, which is the best decision for manufacturer and retailer. While Figure $3 \mathrm{~d}$ shows the system is chaotic, and the prices fluctuate irregularly. It is difficult for manufacturer and retailer to make profits in such a situation. Figure $3 b, c$ indicate that the system is in periodic and quasi periodic states respectively. In the periodic state, the prices eventually tend to the limit cycle and show periodic fluctuation. In quasi periodic state, the prices are not a strict periodic change, and some fluctuation or even bifurcation occurs in system. Therefore, market stability is the best decision environment for manufacturer and retailer, and other three states must be avoided. 


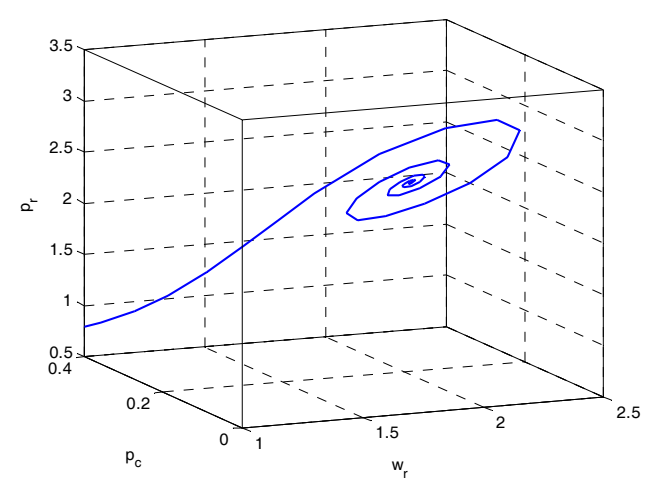

(a)



(c)



(b)

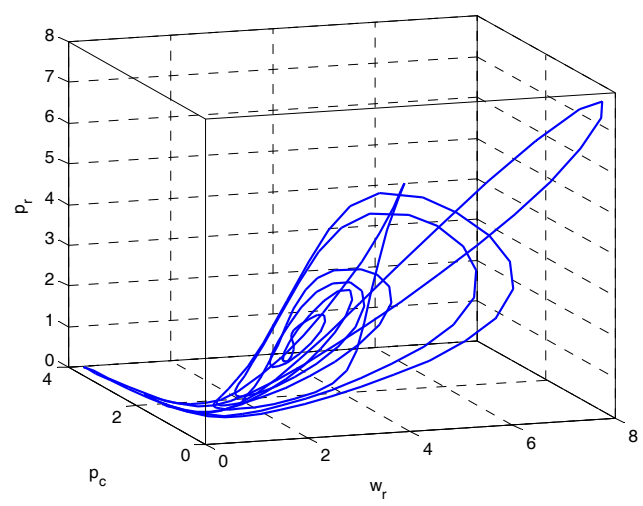

(d)

Figure 3. Attractor. (a) $\tau=1.2$; (b) $\tau=1.6$; (c) $\tau=2.0$; and (d) $\tau=2.18$.

\subsection{The Influence of $v_{w}$ on the Stability and Complexity of Prices and Profits}

Normally, a manufacturer adjusts the wholesale price according to the operation so as to maintain the stability of the profit. But if the wholesale price is adjusted too frequently, it will backfire. We only analyze the effect of $v_{w}$ on the stability and complexity of Equation (13) when the system is stable in this paper, so let $\tau=1.2<\tau_{0}=1.445$. Figure $4 \mathrm{a}-\mathrm{c}$ depict the dynamic behaviors of the system with an increase of the wholesale price adjustment speed. When $v_{w}$ increases from 0 to 0.1 , the wholesale price $w_{r}$ and the retail price $p_{r}$ increase gradually and tend to be 2.421 . There is a bifurcation occurring at $v_{w}=0.725$, the system has lost stability and increased complexity since then. The retail price is based on the wholesale price, so the impact of $v_{w}$ on the retail price and wholesale price is obvious, but the recovery price $p_{c}$ is less affected. The stability region of the system with respect to $v_{w}$ is $[0.1,0.725]$.

On the other hand, the profits of manufacturer and retailer are closely related to price. The fluctuation of prices is bound to cause the instability of profits. Figure $4 \mathrm{~d}$ represents the trend of profit change trends for manufacturer and retailer. It can be seen that the profits have gradually fluctuated considerably when $v_{w}>0.78$. This warns the manufacturer not to rely solely on raising the wholesale price adjustment speed to gain greater profits. Otherwise, it will damage the system equilibrium and bring unnecessary losses to the members of DCLSC. 


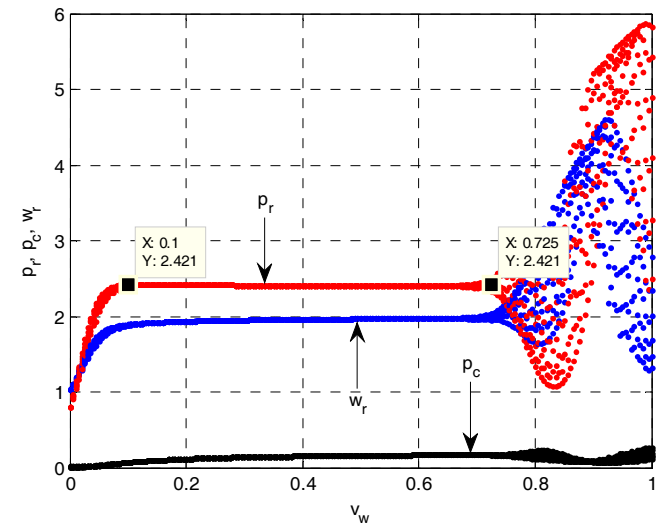

(a)

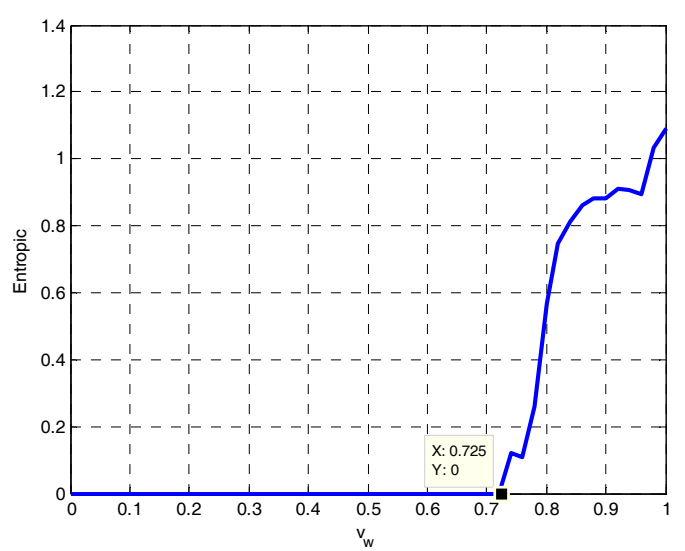

(c)

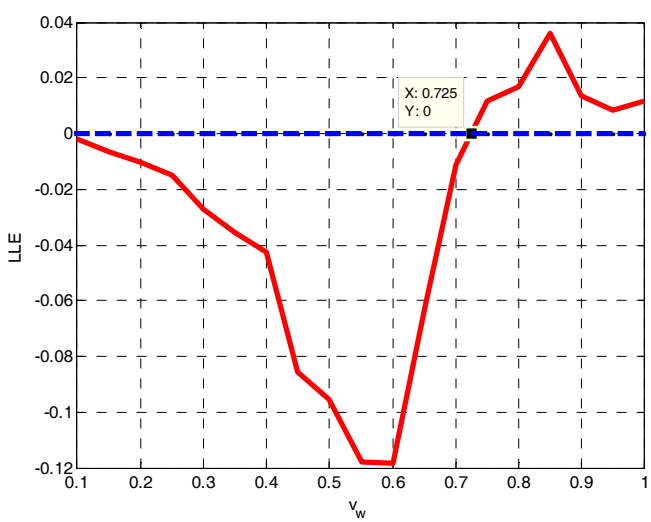

(b)

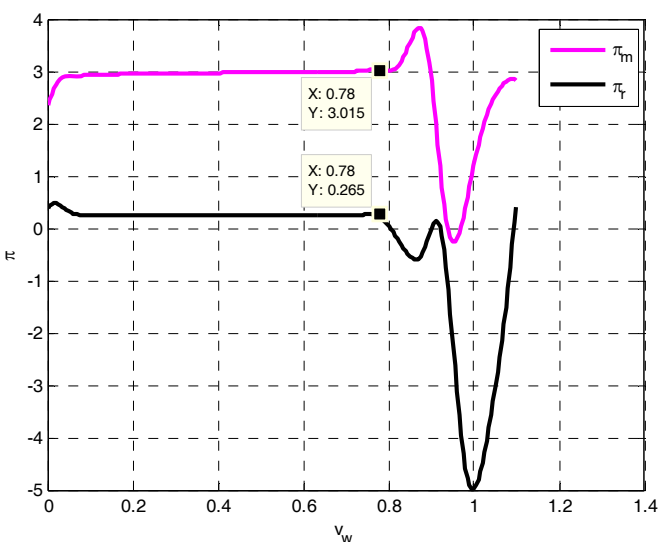

(d)

Figure 4. The impact of $v_{w}$ on the stability and complexity of prices and profits when $\tau=1.2$. (a) bifurcation diagram; (b) the largest Lyapunov exponent diagram; (c) entropy diagram; and (d) profit change trends of manufacturer and retailer.

\subsection{The Influence of $\tau, v_{w}$ on the Stability and Complexity of Prices and Profits}

As one can see from Figure $5 \mathrm{a}$, it describes the change trends of $p_{r}, w_{r}$ and $p_{c}$. The price $p_{r}$ is above, and the price $w_{r}$ is in the middle, while the price $p_{c}$ is below. The price change trends are basically the same. When $\tau$ and $v_{w}$ are larger, Equation (13) is in a state of instability, and becomes more complex. This is shown in Figure 5 b. Manufacturer and retailer make sure that $\left(\tau, v_{w}\right)$ is in the stable region, where entropy value equals zero in Figure $5 b$.

The profit change trends of manufacturer and retailer are basically the same as the prices. The profits rise with an increase of $v_{w}$, while $\tau$ has less impact on profits. We can infer that if manufacturer and retailer want to gain higher profits, they can control the delay parameter in a reasonable range, and then speed up the wholesale price adjustment. But adjusting $\tau$ won't do any good for profits. 




(a)

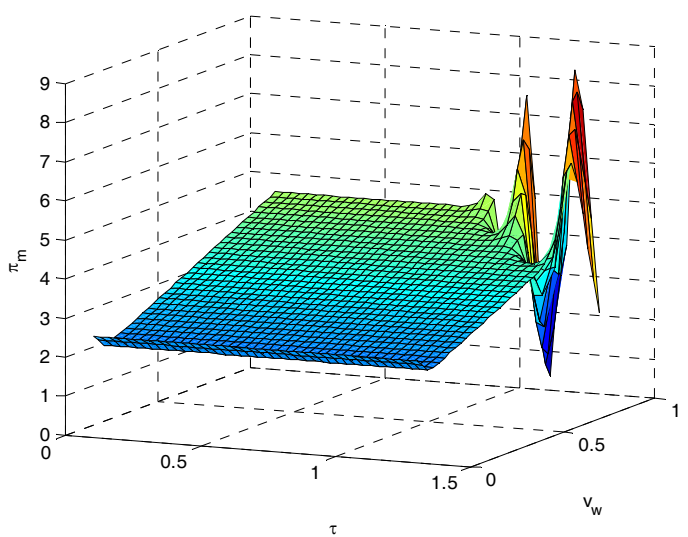

(c)

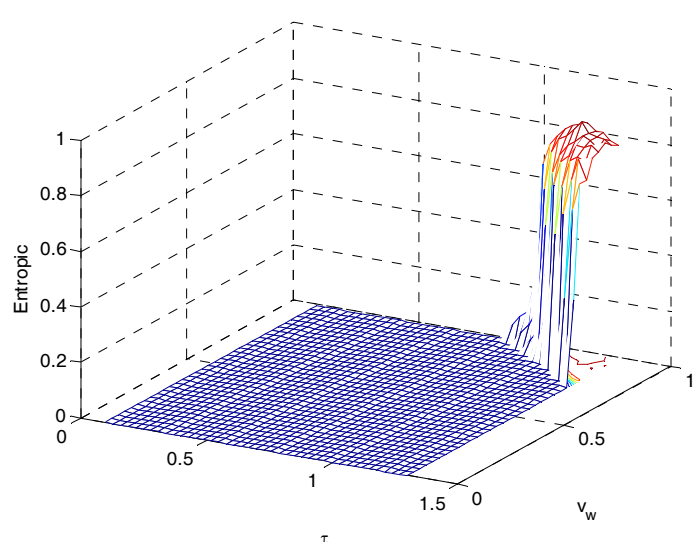

(b)

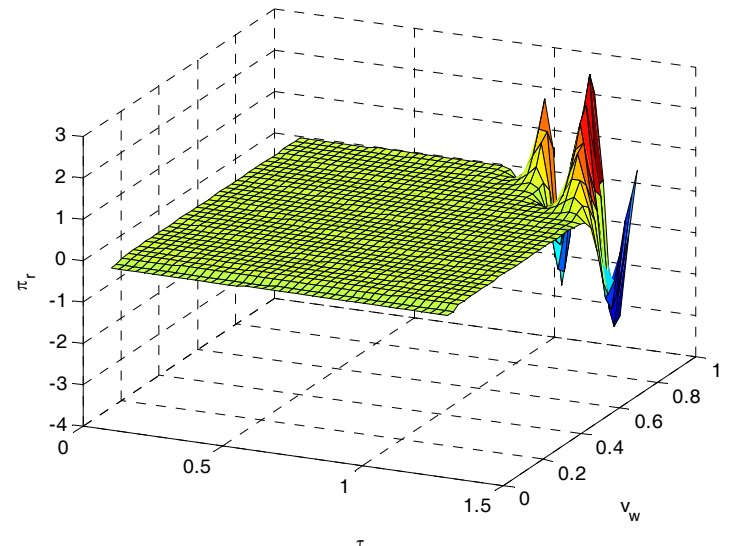

(d)

Figure 5. The impact of $\tau, v_{w}$ on the stability and complexity of profits. (a) price changing trend; (b) entropy diagram; (c) manufacturer's profit; and (d) retailer's profit.

\subsection{The Influence of $\theta$ on the Stability of Prices and Profits}

Increasing the recovery rate of waste products can reduce manufacturers' production costs and obtain more government carbon quota subsidy. It can be seen from Figure $6 \mathrm{a}$, the profits of manufacturer and retailer rise with the increase of $\theta$, but when $\theta>0.765$, the profits will become unstable due to price fluctuations. Figure $6 \mathrm{~b}-\mathrm{d}$ show intuitively the stability change of the system when $\theta=0.6, \theta=0.7$ and $\theta=0.8$ respectively. The fluctuation of prices is positively related to $\theta$. We can deduce that blindly pursue high recovery rate will be more harm than good under other conditions unchanged. 


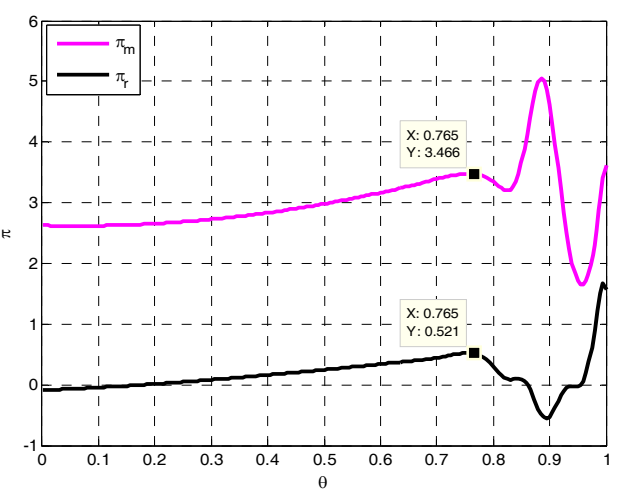

(a)

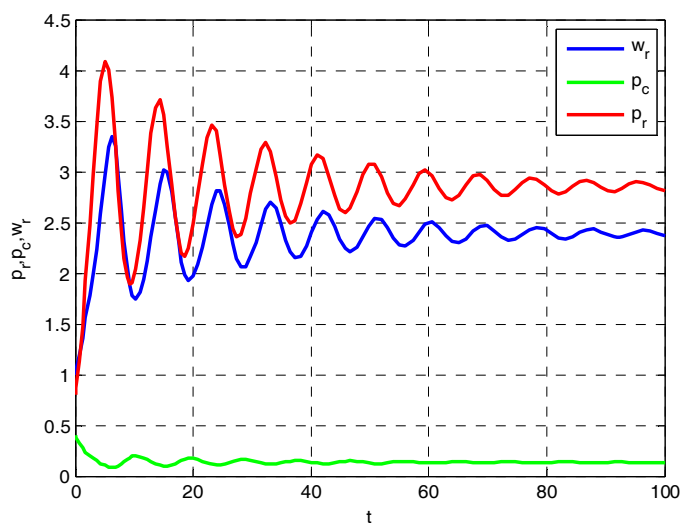

(c)

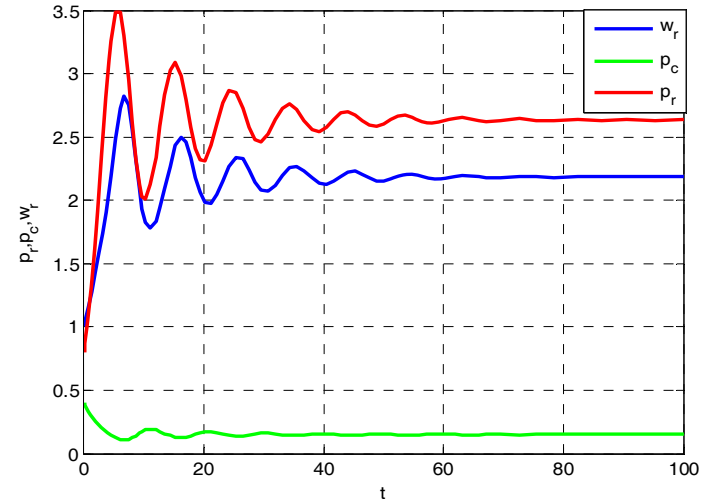

(b)



(d)

Figure 6. Time series diagram and profit change trend with respect to $\theta$ when $\tau=1.2$. (a) profits change trends diagram; (b) $\theta=0.6$; (c) $\theta=0.7$; and (d) $\theta=0.8$.

\subsection{The Influence of $p_{e}$ on the Stability of Prices and Profits}

Manufacturers usually increase direct prices to make more profits. Now we are concerned about the impact of direct price on prices and profits. As can be seen from Figure 7a, the profit of manufacturer raises significantly with the increase of direct price, but retailer's profit almost remains unchanged.

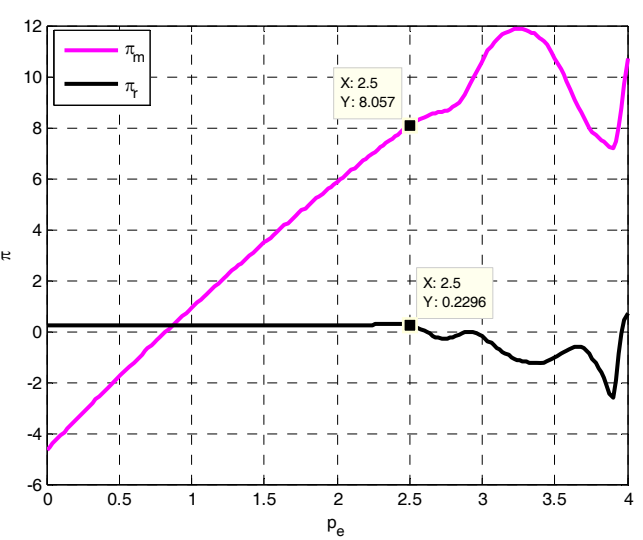

(a)

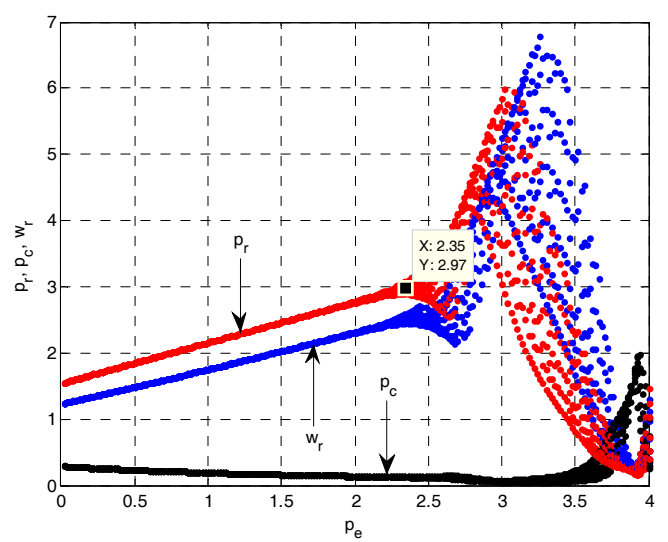

(b)

Figure 7. Cont. 


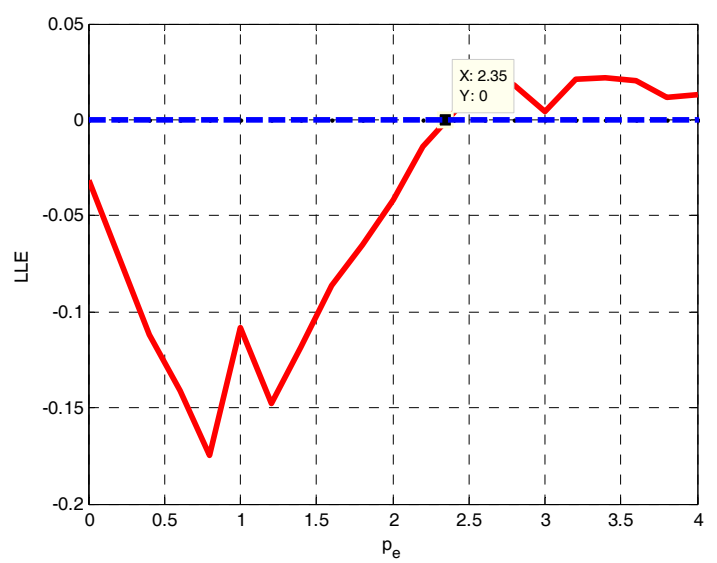

(c)

Figure 7. The impact of $p_{e}$ on the stability of prices and profits when $\tau=1$.2. (a) profit change trends diagram; (b) bifurcation diagram; and (c) the largest Lyapunov exponent diagram.

However, the direct price cannot increase unlimitedly, and if $p_{e}>2.5$, retailer's profit will slow down, there has been a marked loss. Figure $7 \mathrm{~b}, \mathrm{c}$ describe the effects of $p_{e}$ on prices. It results in an increase in wholesale and retail price when $p_{e}$ moves from 0 to 2.35 , but the recovery price is almost unaffected. If $p_{e}>2.35$, the system will go into unstable state, or even enter chaos, so we can speculate that the manufacturer can interfere with retail prices by adjusting the direct price or wholesale price. The manufacturer gains much more profits than the retailer by increasing the direct price, but if the direct price exceeds a reasonable range, it will seriously damage the interests of the retailer.

\subsection{The Influence of Government Intervention on the Stability of Manufacturer's Profit}

Carbon emissions of unit product, carbon tax, and carbon quota subsidy affect manufacturer's cost and profit. Figure 8a shows the effects of carbon quota subsidy $q_{f}$, carbon emissions of unit new products $e_{p}$, and carbon emissions of unit remanufactured products $e_{r}$ on the manufacturer's profit $\pi_{m}$. We find that the increase of $e_{p}$ will lead to lower $\pi_{m}$, while $e_{r}$ has little impact on $\pi_{m}$. In addition, manufacturer's profit $\pi_{m}$ is positively related to $q_{f}$. Therefore, the manufacturer should increase the recycling and remanufacturing of waste products, and strive for more government carbon quota subsidies to raise profits.

Figure $8 \mathrm{~b}$ describes the effects of carbon tax $c_{e}$, carbon emissions of unit new products $e_{p}$ and carbon emissions per unit of remanufactured products $e_{r}$ on the manufacturer's profit $\pi_{m}$. The increase of $c_{e}$ will cause a significant decrease in $\pi_{m}$ when $e_{p}$ is relatively larger. Therefore, the government generally regulates the energy-saving and emission-reduction of manufacturers by using a carbon tax, and forces manufacturer to increase investment and reduce carbon emissions. If the $c_{e}$ is lower, $e_{p}$ and $e_{r}$ have less impact on $\pi_{m}$. However, if the $c_{e}$ is higher, $\pi_{m}$ decreases with the increase of $e_{p}$. Regardless of the carbon tax, the carbon emissions per unit of remanufactured product have little impact on the manufacturer's profit, so the manufacturer should actively carry out recycling and reuse of waste products. 


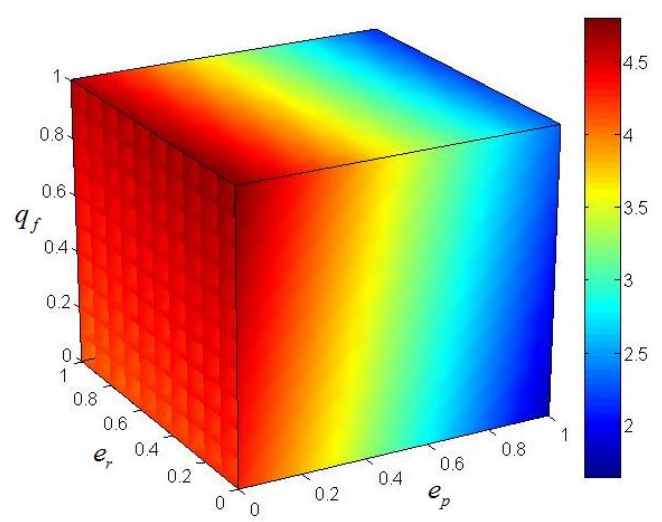

(a)

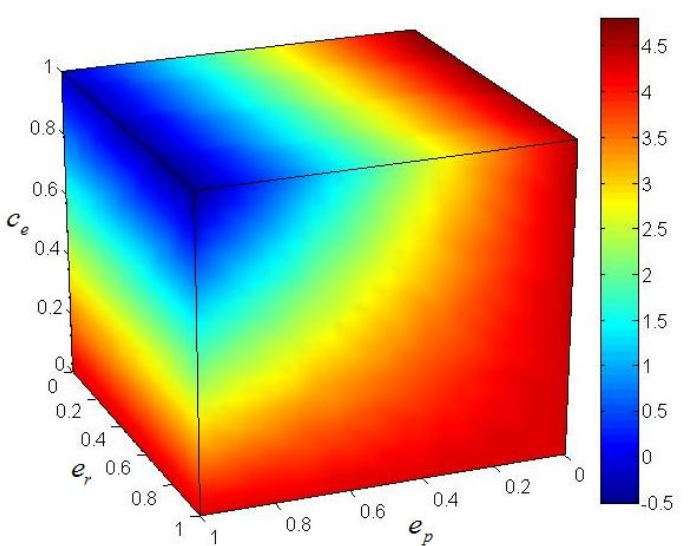

(b)

Figure 8. The impact of government intervention on the manufacturer's profit $\tau=1.2$. (a) $q_{f}, e_{r}, e_{p}$; and (b) $c_{e}, e_{r}, e_{p}$.

\section{Chaos Control}

Based on the above analysis, we know that if the system is unstable or chaotic, it will cause sharp fluctuations in prices and profits, and bring unpredictable losses to the manufacturer and retailer. Therefore, it is necessary to take measures to avoid or delay systematic bifurcation, or to make the unstable system return to stable state. In this paper, the delayed feedback control method is adopted to control the chaotic system.

In Figure 3d, the system is chaotic when $\tau=2.18$, its corresponding time series diagram is shown in Figure 9. It is clear that the price fluctuates irregularly. At this time, the wholesale price is not always smaller than the retail price. Obviously, this will have a bad influence on retailer's profit.

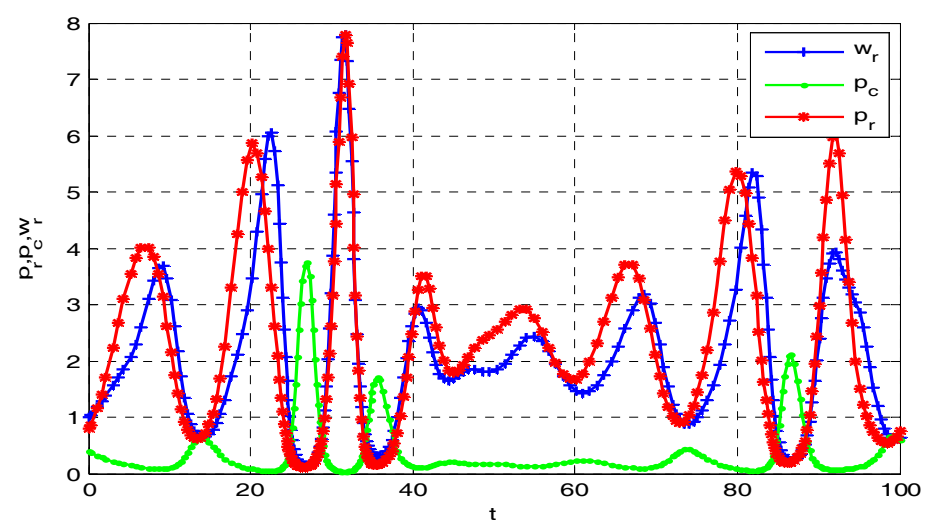

Figure 9. Time series diagram when $\tau=2.18$.

For that reason, adding control item on Equation (13), we can get:

$$
\left\{\begin{array}{l}
\dot{p_{r}}=0.4 p_{r}\left[0.62+0.9 p_{c}\left(t-\tau_{c}\right)-p_{r}\left(t-\tau_{r}\right)+0.5 w_{r}\left(t-\tau_{w}\right)\right]-\mu\left(p_{r}-p_{r}\left(t-\tau_{r}\right)\right) \\
\dot{p_{c}}=0.5 p_{c}\left[-0.848-0.8 p_{c}\left(t-\tau_{c}\right)+0.9 p_{r}\left(t-\tau_{r}\right)-0.4 w_{r}\left(t-\tau_{w}\right)\right]-\mu\left(p_{c}-p_{c}\left(t-\tau_{c}\right)\right) \\
\dot{w_{r}}=0.6 w_{r}\left[0.92+0.4 p_{c}\left(t-\tau_{c}\right)-0.5 p_{r}\left(t-\tau_{r}\right)\right]
\end{array}\right.
$$

where $\mu$ is the control parameter. Next, we focus on the influence of $\mu$ on Equation (14), which is shown in Figure 10. Equation (14) is unstable when $\mu<0.206$. There is a bifurcation occurs when $\mu=0.206$. In addition to the situation, Equation (14) is stable. We can also find that $\mu$ is negatively related to the 
stability and complexity of the system. That is to say, the control parameter $\mu$ can directly affect the stability and the complexity of Equation (14), it will return to stable state as long as $\mu>0.206$.

Let's observe the chaos control effect for $\mu=0.1<0.206$ and $\mu=0.25>0.206$ respectively. It can be seen from Figure 11 that Equation (14) is still unstable when $\mu=0.1$. After a long game, the prices of manufacturer and retailer will tend to a limit cycle. That is to say, the ultimate purpose of control is not achieved, but comparing Figures 9 and 11a, we find that Equation (14) has been transformed from chaotic state into periodic state. This show the control measures have played a certain role. The retail price has already greater than the wholesale price, but the cyclical price fluctuations are not good for the decisions of manufacturer and retailer.

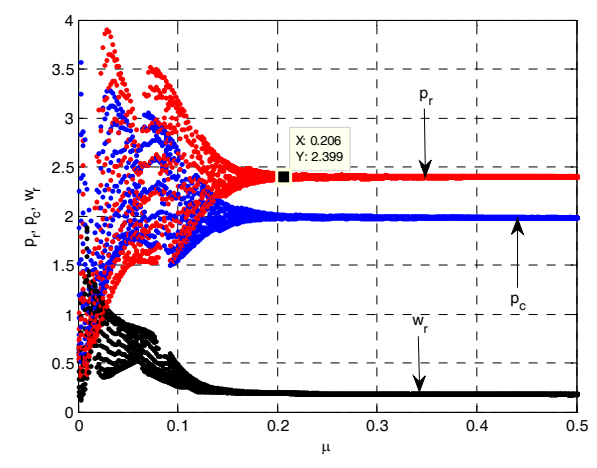

(a)

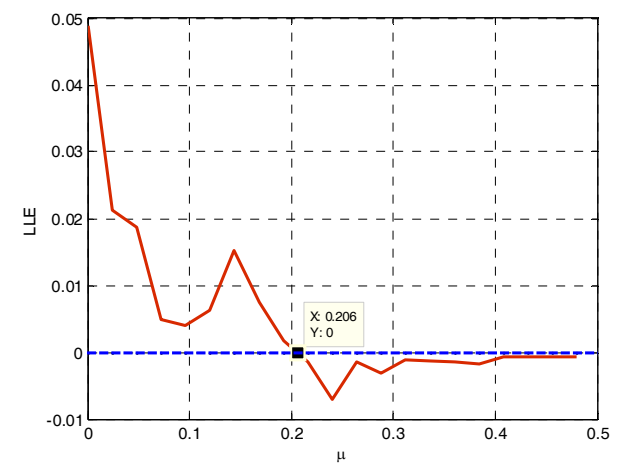

(b)

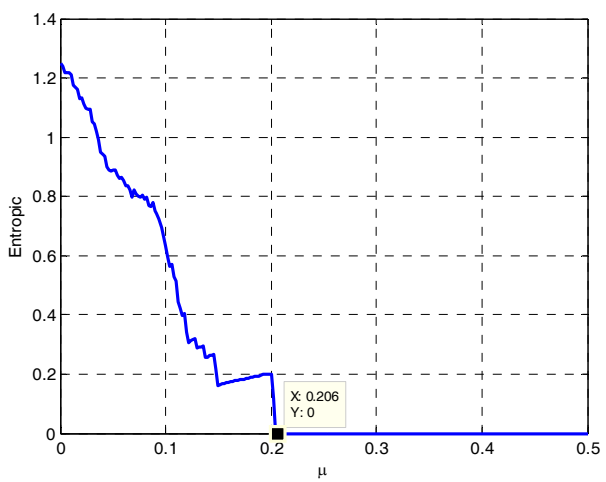

(c)

Figure 10. The impact of $\mu$ on the stability and complexity of Equation (14) when $\tau=2.18$. (a) bifurcation diagram; (b) the largest Lyapunov exponent diagram; and (c) entropy diagram.

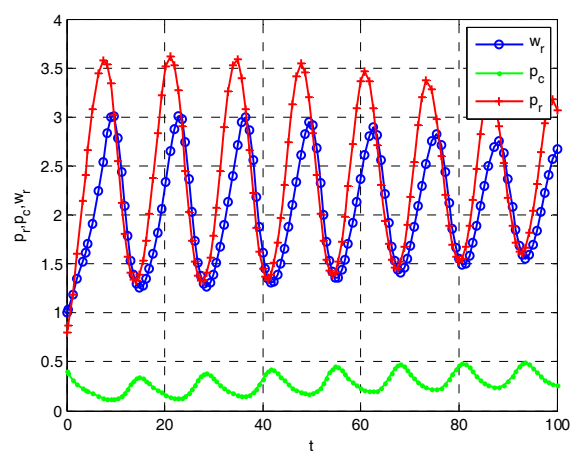

(a)

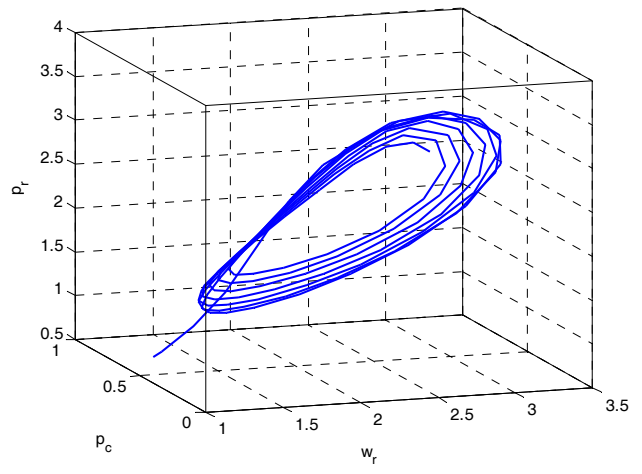

(b)

Figure 11. Equation (14) is unstable when $\mu=0.1$ and $\tau=2.18$. (a) time series diagram; and (b) attractor. 
However, Equation (14) returns to stable state when $\mu=0.25$, which is shown in Figure 12. Equation (14) has changed from chaotic state to stable state by adjusting $\mu$. After game, the prices will tend to equilibrium point, then manufacturer and retailer can get the maximum profits. The chaotic control is realized successfully by using delayed feedback control method, and the price stability of DCLSC is ensured by adjusting the control parameter.



(a)



(b)

Figure 12. Equation (14) is stable when $\mu=0.25$ and $\tau=2.18$. (a) time series diagram; and (b) attractor.

\section{Conclusions}

This paper constructs a DCLSC with carbon emissions and government subsidies, which is composed of a manufacturer and a retailer. The manufacturer is responsible for the production of new products and remanufactured products. The retailer is responsible for the recycling of waste products and reselling them to manufacturer. The manufacturer sells new products and remanufactured products through a direct channel and retailer channel, respectively. There is price competition between the two channels. A continuous price game model with delays is established in DCLSC, and the local stability of the model is analyzed.

In the numerical simulation and analysis, the influence of parameters such as bifurcation and chaos on the dynamic characteristics of the model is investigated. In order to overcome the adverse effects caused by chaos, we adopt the delayed feedback control method to make the chaotic system returns to the stable state successfully.

The following conclusions can be drawn from this study: (1) the local stability conditions of the equilibrium point of the model are given; (2) the delay of retail price decisions or the sum of wholesale price delay and recovery price delay shouldn't be too large. If they go beyond a certain range, the price game system will lose stability and even enter chaos. This will increase the complexity of the system and result in instability of profits; (3) the profits of manufacturer and retailer are positively related to the adjustment speed of the wholesale price when $\tau$ is smaller, but the adjustment speed of the wholesale price should be controlled within a reasonable range, otherwise it will cause the fluctuation of profits when $\tau$ is bigger; (4) the improvement of recovery rate of waste products will increase the profits of manufacturer and retailer, but it must be controlled within a reasonable range, otherwise it will cause serious damage to the profit of the retailer; (5) the growth of direct price will lead to increase of retail price and manufacturer's profit, but the retailer's profit is almost unchanged; (6) the government can adjust the manufacturer's profit through carbon taxes and carbon quota subsidies. The manufacturer's profit is negatively related and positively related to carbon taxes and carbon quotas subsidies, respectively. Therefore, the government can stimulate manufacturers to reduce carbon emissions and encourage them to improve the recycling and remanufacturing of waste products by means of these two approaches; (7) the delayed feedback control method can be taken to 
make unstable or chaotic systems get rid of disadvantage, and to ensure manufacturer and retailer make the right decisions in stable system.

The paper only considers the government subsidy to the manufacturer. As a next step, we will discuss the sharing of subsidy between manufacturer and retailer by using subsidy sharing contract. In addition, we can also study the government subsidy to retailer directly, and increase the enthusiasm of retailer to participate in the recycling of waste products.

Acknowledgments: The authors thank the reviewers for their careful reading and pertinent suggestions. The research was supported by The Natural Science Research Project of Education Department in Anhui Province (KJ2015ZD02), The Humanities and Social Science Research Project of Education Department in Anhui Province (SK2017A0434), The National Natural Science Foundation of China (11626033), The Philosophy and Social Science Planning Project of Anhui Province (AHSKQ2016D29); The University Outstanding Young Talent Support Project of Anhui Province (gxyq2017101); The Social Science Planning Project of Bengbu City (BB17C021).

Author Contributions: Daoming Dai proposed research ideas and constructed the model; Fengshan Si suggested research methods and provided numerical simulation; Jing Wang performed mathematical derivation. These authors wrote this paper together and contributed equally to this work. All authors have read and approved the final manuscript.

Conflicts of Interest: The authors declare no conflict of interest.

\section{Appendix A}

Proof of Theorem 1

Proof. Equation (12) can be linearized through the Jacobian matrix is as follows [25]:

$$
\left\{\begin{array}{l}
\dot{p_{r}}=J_{11} p_{r}+J_{12} p_{r}\left(t-\tau_{r}\right)+J_{14} p_{c}\left(t-\tau_{c}\right)+J_{16} w_{r}\left(t-\tau_{w}\right) \\
\dot{p_{c}}=J_{22} p_{r}\left(t-\tau_{r}\right)+J_{23} p_{c}+J_{24} p_{c}\left(t-\tau_{c}\right)+J_{26} w_{r}\left(t-\tau_{w}\right) \\
\dot{w_{r}}=J_{32} p_{r}\left(t-\tau_{r}\right)+J_{34} p_{c}\left(t-\tau_{c}\right)+J_{35} w_{r}
\end{array}\right.
$$

where:

$$
\begin{aligned}
& J_{11}=v_{r} \theta s+v_{r}(\theta k+b) p_{c}^{*}+c v_{r} p_{e}-v_{r} 2 b p_{r}^{*}+v_{r} b w_{r}^{*}-v_{r} b b_{r}, J_{12}=-2 b v_{r} p_{r}^{*}, J_{13}=0, \\
& J_{14}=(\theta k+b) v_{r} p_{r}^{*}, J_{15}=0, J_{16}=b v_{r} p_{r}^{*}, J_{21}=0, J_{22}=(b+k \theta) v_{c} p_{c}^{*}, \\
& J_{23}=-\theta s v_{c}-2 \theta k v_{c} p_{c}^{*}-c v_{c} p_{e}+(b+k \theta) v_{c} p_{r}^{*}+k \theta b_{r} v_{c}-k \theta w_{r}^{*} v_{c}, J_{24}=-2 \theta k v_{c} p_{c}^{*}, \\
& J_{25}=0, J_{26}=-k \theta v_{c} p_{c}^{*}, J_{31}=0, J_{32}=-b v_{w} w_{r}^{*}, J_{33}=0, J_{34}=\theta k v_{w} w_{r}^{*}, \\
& J_{35}=\theta s v_{w}+\theta k v_{w} p_{c}^{*}+c v_{w} p_{e}-b v_{w} p_{r}^{*}, J_{36}=0 .
\end{aligned}
$$

The characteristic determinant of Equation (A1) is:

$$
|\lambda I-J|=\left|\begin{array}{lll}
\lambda-J_{11}^{\prime} & -J_{12}^{\prime} & -J_{13}^{\prime} \\
-J_{21}^{\prime} & \lambda-J_{22}^{\prime} & -J_{23}^{\prime} \\
-J_{31}^{\prime} & -J_{32}^{\prime} & \lambda-J_{33}^{\prime}
\end{array}\right|=0
$$

where:

$J_{11}^{\prime}=J_{11}+J_{12} e^{-\lambda \tau_{r}}, J_{12}^{\prime}=J_{14} e^{-\lambda \tau_{c}}, J_{13}^{\prime}=J_{16} e^{-\lambda \tau_{w}}, J_{21}^{\prime}=J_{22} e^{-\lambda \tau_{r}}, J_{22}^{\prime}=J_{23}+J_{24} e^{-\lambda \tau_{c}}$, $J_{23}^{\prime}=J_{26} e^{-\lambda \tau_{w}}, J_{31}^{\prime}=J_{32} e^{-\lambda \tau_{r}}, J_{32}^{\prime}=J_{34} e^{-\lambda \tau_{c}}, J_{33}^{\prime}=J_{35}$.

The characteristic equation of Equation (A1) is:

$$
\lambda^{3}+A_{2} \lambda^{2}+\left(B_{2} \lambda^{2}+B_{1} \lambda\right) e^{-\lambda \tau_{r}}+\left(C_{1} \lambda+C_{0}\right) e^{-\lambda\left(\tau_{c}+\tau_{w}\right)}+D_{0} e^{-\lambda\left(\tau_{r}+\tau_{c}+\tau_{w}\right)}=0
$$

where:

$A_{2}=-s \theta v_{w}-c p_{e} v_{w}-k \theta v_{w} p_{c}^{*}+b v_{w} p_{r}^{*}$ 
$B_{2}=2 k^{2} \theta^{2} b_{r} v_{c}^{2} p_{c}^{*}-2 k s \theta^{2} v_{c}^{2} p_{c}^{*}-2 c k \theta p_{e} v_{c}^{2} p_{c}^{*}+\ldots+2 b^{2} v_{r}^{2} p_{r}^{*} w_{r}^{*}+2 b v_{r} p_{c}^{*} p_{r}^{*} v_{r}(b+k \theta)$,

$B_{1}=2 k s^{2} \theta^{3} v_{c}^{2} v_{w} p_{c}^{*}-2 k^{2} s \theta^{3} b_{r} v_{c}^{2} v_{w} p_{c}^{*}+4 c k s \theta^{2} p_{e} v_{c}^{2} v_{w} p_{c}^{*}+\ldots+2 b^{2} v_{r} v_{w} p_{c}^{*} p_{r}^{* 2} v_{r}(b+k \theta)$,

$C_{1}=-b^{2} v_{c} v_{r} p_{c}^{*} p_{r}^{*}-2 b k \theta v_{c} v_{r} p_{c}^{*} p_{r}^{*}-k^{2} \theta^{2} v_{c} v_{r} p_{c}^{*} p_{r}^{*}+\ldots-4 b k^{2} \theta^{2} v_{c}^{2} v_{r} p_{c}^{* 2} p_{r}^{*} w_{r}^{*} v_{r}(b+k \theta)$,

$C_{0}=b^{2} s \theta v_{c} v_{r} v_{w} p_{c}^{*} p_{r}^{*}+2 b k s \theta^{2} v_{c} v_{r} v_{w} p_{c}^{*} p_{r}^{*}+\ldots-4 b^{2} k^{2} \theta^{2} v_{c}^{2} v_{r} v_{w} p_{c}^{* 2} p_{r}^{* 2} w_{r}^{*} v_{r}(b+k \theta)$,

$D_{0}=-2 b^{2} k \theta v_{c} v_{r} v_{w} p_{c}^{*} p_{r}^{*} w_{r}^{*}-2 b k^{2} \theta^{2} v_{c} v_{r} v_{w} p_{c}^{*} p_{r}^{*} w_{r}^{*}+\ldots+2 b k^{2} \theta^{2} v_{c} v_{r} v_{w} p_{c}^{* 2} p_{r}^{*} w_{r}^{*} v_{r}(b+k \theta)$.

Set $\tau_{r}=\tau_{c}+\tau_{w}=\tau$, Equation (A3) can be simplified as:

$$
\lambda^{3}+A_{2} \lambda^{2}+\left(B_{2} \lambda^{2}+B_{1} \lambda\right) e^{-\lambda \tau}+\left(C_{1} \lambda+C_{0}\right) e^{-\lambda \tau}+D_{0} e^{-2 \lambda \tau}=0
$$

Both sides of Equation (A4) multiplied by $e^{\lambda \tau}$ can be obtained:

$$
\left(\lambda^{3}+A_{2} \lambda^{2}\right) e^{\lambda \tau}+B_{2} \lambda^{2}+B_{1} \lambda+C_{1} \lambda+C_{0}+D_{0} e^{-\lambda \tau}=0
$$

Let $\lambda=i \omega(\omega>0)$ be the root of Equation (A5). Substituting $\lambda=i \omega(\omega>0)$ into Equation (A5) and separating the real and imaginary parts, we get:

$$
\left\{\begin{array}{l}
-\omega^{3} \cos \omega \tau+\left(D_{0}-A_{2} \omega^{2}\right) \sin \omega \tau=-\left(B_{1} \omega+C_{1} \omega\right) \\
\left(D_{0}-A_{2} \omega^{2}\right) \cos \omega \tau+\omega^{3} \sin \omega \tau=B_{2} \omega^{2}-C_{0}
\end{array}\right.
$$

From Equation (A6), we have:

$$
\left\{\begin{array}{l}
\sin (\omega \tau)=\frac{B_{2} \omega^{5}-\left(-A_{2} B_{1}-A_{2} C_{1}+C_{0}\right) \omega^{3}-\left(B_{1} D_{0}+C_{1} D_{0}\right) \omega}{2\left(D_{0}-A_{2} \omega^{2}\right) \omega^{3}} \\
\cos (\omega \tau)=\frac{B_{2} \omega^{5}-\left(A_{2} B_{1}+A_{2} C_{1}+C_{0}\right) \omega^{3}+\left(B_{1} D_{0}+C_{1} D_{0}\right) \omega}{2\left(D_{0}-A_{2} \omega^{2}\right) \omega^{3}}
\end{array}\right.
$$

Squaring and adding both Equations (A6), then we have:

$$
\omega^{6}+z_{2} \omega^{4}+z_{1} \omega^{2}+z_{0}=0
$$

where:

$z_{2}=A_{2}^{2}-B_{2}^{2}, z_{1}=2 B_{2} C_{0}-2 D_{0} A_{2}-B_{1}^{2}-C_{1}^{2}-2 B_{1} C_{1}, z_{0}=D_{0}^{2}-C_{0}^{2}$.

Let $s=\omega^{2}$, Equation (A8) is simplified as:

$$
s^{3}+z_{2} s^{2}+z_{1} s+z_{0}=0
$$

We define:

$$
h(s)=s^{3}+z_{2} s^{2}+z_{1} s+z_{0}
$$

(a) If $z_{0}<0$, then Equation (A9) has at least one positive root.

(b) If $z_{0} \geq 0$ and $\triangle=z_{2}^{2}-3 z_{1}<0$, then Equation (A9) has no positive roots.

(c) If $z_{0} \geq 0$, then Equation (A9) has positive roots if and only if $s_{1}=\left(-z_{2}+\sqrt{\triangle}\right) / 3>0$ and $h\left(s_{1}\right) \leq 0$.

Without losing generality, it is assumed that Equation (A9) has three positive roots, namely $s_{1}, s_{2}, s_{3}$. So $\omega_{1}=\sqrt{s_{1}}, \omega_{2}=\sqrt{s_{2}}, \omega_{3}=\sqrt{s_{3}}$.

Then, for every fixed $\omega_{n}(n=1,2,3)$, there exists a sequence $\left\{\tau_{n}^{(\mathrm{j})} \mid n=1,2,3 ; j=0,1,2, \ldots\right\}$ which satisfies Equation (A5). From Equation (A7), we can get:

$$
\tau_{n}^{(\mathrm{j})}=\frac{1}{\omega_{n}} \arccos \left(\frac{B_{2} \omega_{n}^{5}-\left(A_{2} B_{1}+A_{2} C_{1}+C_{0}\right) \omega_{n}^{3}+\left(B_{1} D_{0}+C_{1} D_{0}\right) \omega_{n}}{2\left(D_{0}-A_{2} \omega_{n}^{2}\right) \omega_{n}^{3}}\right)+\frac{2 j \pi}{\omega_{n}}, n=1,2,3 ; j=0,1,2, \ldots
$$


Let $\tau_{0}=\min \left\{\tau_{n}^{(\mathrm{j})} \mid n=1,2,3 ; j=0,1,2, \ldots\right\}=\min \left\{\tau_{n}^{(0)} \mid n=1,2,3\right\}=\tau_{n_{0}}$, then $\omega_{0}=\omega_{n_{0}} \in$ $\left\{\omega_{1}, \omega_{2}, \omega_{3}\right\}$. Thus, we obtain $\tau_{0}$ as follows:

$$
\tau_{0}=\frac{1}{\omega_{0}} \arccos \left(\frac{B_{2} \omega_{0}^{5}-\left(A_{2} B_{1}+A_{2} C_{1}+C_{0}\right) \omega_{0}^{3}+\left(B_{1} D_{0}+C_{1} D_{0}\right) \omega_{0}}{2\left(D_{0}-A_{2} \omega_{0}^{2}\right) \omega_{0}^{3}}\right)
$$

Then, we can draw the following conclusions [26,27]:

Lemma 1. If conditions $(a)-(c)$ have at least one hold, then Equation (A5) has a pair of purely imaginary roots $\pm i \omega_{0}$ when $\tau=\tau_{0}$.

The following, we take the derivative with $\tau$ in Equation (A5), we have:

$$
\left[\frac{d \lambda}{d \tau}\right]^{-1}=\frac{\left(3 \lambda^{2}+2 A_{2} \lambda\right) e^{\lambda \tau}+2 B_{2} \lambda+B_{1}+C_{1}}{B_{2} \lambda^{3}+\left(B_{1}+C_{1}\right) \lambda^{2}+C_{0} \lambda+\lambda 2 D_{0} e^{-\lambda \tau}}-\frac{\tau}{\lambda}
$$

Then:

$$
\operatorname{Re}\left[\frac{d \lambda\left(\tau_{0}\right)}{d \tau}\right]_{\lambda=i \omega_{0}}^{-1}=\frac{Q_{3}+Q_{4}}{Q_{1}^{2}+Q_{2}^{2}}
$$

where:

$Q_{1}=2 D_{0} \omega_{0} \sin \omega_{0} \tau_{0}-\left(B_{1}+C_{1}\right) \omega_{0}^{2}, Q_{2}=C_{0} \omega_{0}-B_{2} \omega_{0}^{3}+2 D_{0} \omega_{0} \sin \omega_{0} \tau_{0}$,

$Q_{3}=B_{1} R+C_{1} R-2 A_{2} \omega_{0} R \sin \omega_{0} \tau_{0}-3 R \omega_{0}^{2} \cos \omega_{0} \tau_{0}$,

$Q_{4}=2 I B_{2} \omega_{0}+2 I A_{2} \omega_{0} \cos \omega_{0} \tau_{0}-3 I \omega_{0}^{2} \sin \omega_{0} \tau_{0}$.

Lemma 2. If $Q_{3}+Q_{4} \neq 0$, then $\left.\frac{d \operatorname{Re} \lambda\left(\tau_{0}\right)}{d \tau}\right|_{\lambda=i \omega_{0}}=\operatorname{Re}\left[\frac{d \lambda\left(\tau_{0}\right)}{d \tau}\right]_{\lambda=i \omega_{0}}^{-1} \neq 0$. Thus, it satisfies the transversal condition.

We can obtain Theorem 1 according to Lemmas 1 and 2.

\section{References}

1. Turki, S.; Didukh, S.; Sauvey, C.; Rezg, N. Optimization and Analysis of a Manufacturing-RemanufacturingTransport-Warehousing System within a Closed-Loop Supply Chain. Sustainability 2017, 9, 561. [CrossRef]

2. Ji, J.; Zhang, Z.; Yang, L. Carbon emission reduction decisions in the retail-/dual-channel supply chain with consumers' preference. J. Clean. Prod. 2017, 141, 852-867. [CrossRef]

3. Xu, Z.; Pokharel, S.; Elomri, A.; Mutlu, F. Emission policies and their analysis for the design of hybrid and dedicated closed-loop supply chains. J. Clean. Prod. 2017, 142, 4152-4168. [CrossRef]

4. Zheng, X.; Zhu, P.; Chen, S. Research on Optimization of Closed Loop Supply Chain Integrated Model Based on Low Carbon. Chem. Eng. 2016, 51, 967-972.

5. Fahimnia, B.; Sarkis, J.; Dehghanian, F.; Banihashemi, N.; Rahman, S. The impact of carbon pricing on a closed-loop supply chain: An Australian case study. J. Clean. Prod. 2013, 59, 210-225. [CrossRef]

6. Bazan, E.; Jaber, M.Y.; Zanoni, S. Carbon emissions and energy effects on a two-level manufacturer-retailer closed-loop supply chain model with remanufacturing subject to different coordination mechanisms. Int. J. Prod. Econ. 2017, 183, 394-408. [CrossRef]

7. Qi, Q.; Wang, J.; Bai, Q. Pricing decision of a two-echelon supply chain with one supplier and two retailers under a carbon cap regulation. J. Clean. Prod. 2017, 151, 286-302. [CrossRef]

8. Tao, Z.G.; Guang, Z.Y.; Hao, S.; Song, H.J.; Xin, D.G. Multi-period closed-loop supply chain network equilibrium with carbon emission constraints. Resour. Conserv. Recycl. 2015, 104, 354-365. [CrossRef]

9. Sheu, J.-B.; Chen, Y.J. Impact of government financial intervention on competition among green supply chains. Int. J. Prod. Econ. 2012, 138, 201-213. [CrossRef] 
10. Wang, C.; Wang, W.; Huang, R. Supply chain enterprise operations and government carbon tax decisions considering carbon emissions. J. Clean. Prod. 2017, 152, 271-280. [CrossRef]

11. Fareeduddin, M.; Hassan, A.; Syed, M.N.; Selim, S.Z. The Impact of Carbon Policies on Closed-Loop Supply Chain Network Design. Procedia CIRP 2015, 26, 335-340. [CrossRef]

12. He, R.; Xiong, Y.; Lin, Z. Carbon emissions in a dual channel closed loop supply chain: The impact of consumer free riding behavior. J. Clean. Prod. 2016, 134, 384-394. [CrossRef]

13. Li, J.; Du, W.; Yang, F.; Hua, G. The Carbon Subsidy Analysis in Remanufacturing Closed-Loop Supply Chain. Sustainability 2014, 6, 3861-3877. [CrossRef]

14. Ma, W.; Zhao, Z.; Ke, H. Dual-channel closed-loop supply chain with government consumption-subsidy. Eur. J. Oper. Res. 2013, 226, 221-227. [CrossRef]

15. Zhao, S.; Zhu, Q.; Cui, L. A decision-making model for remanufacturers: Considering both consumers' environmental preference and the government subsidy policy. Resour. Conserv. Recycl. 2016. [CrossRef]

16. Mitra, S.; Webster, S. Competition in remanufacturing and the effects of government subsidies. Int. J. Prod. Econ. 2008, 111, 287-298. [CrossRef]

17. Yang, D.; Xiao, T. Pricing and green level decisions of a green supply chain with governmental interventions under fuzzy uncertainties. J. Clean. Prod. 2017, 149, 1174-1187. [CrossRef]

18. Heydari, J.; Govindan, K.; Jafari, A. Reverse and closed loop supply chain coordination by considering government role. Transp. Res. Part D 2017, 52, 379-398. [CrossRef]

19. Xie, L.; Ma, J. Study the complexity and control of the recycling-supply chain of China's color TVs market based on the government subsidy. Commun. Nonlinear Sci. Numer. Simul. 2016, 38, 102-116. [CrossRef]

20. Ma, J.; Wang, H. Complexity analysis of dynamic noncooperative game models for closed-loop supply chain with product recovery. Appl. Math. Model. 2014, 38, 5562-5572. [CrossRef]

21. Guo, Y.; Ma, J. Research on game model and complexity of retailer collecting and selling in closed-loop supply chain. Appl. Math. Model. 2013, 37, 5047-5058. [CrossRef]

22. Zhou, L.; Naim, M.M.; Disney, S.M. The impact of product returns and remanufacturing uncertainties on the dynamic performance of a multi-echelon closed-loop supply chain. Int. J. Prod. Econ. 2017, 183, 487-502. [CrossRef]

23. Fudenberg, D.; Levine, D. Learning and Evolution: Where Do We Stand? Learning in games. Eur. Econ. Rev. 1998, 42, 631-639. [CrossRef]

24. Kuznetsov, Y.A. Elements of Applied Bifurcation Theory; Springer: New York, NY, USA, 2004.

25. Ma, J.; Si, F. Complex dynamics of a continuous Bertrand duopoly game model with two-stage delay. Entropy 2016, 18, 266. [CrossRef]

26. Ruan, S.; Wei, J. On the zeros of transcendental functions to stability of delay differential equations with two delays. Dyn. Contin. Discret. Impuls. Syst. A Math. Anal. 2003, 10, 863-874.

27. Wang, J.; Si, F.; Wang, Y.; Duan, S. Entropy and Stability Analysis of Delayed Energy Supply-Demand Model. Entropy 2016, 18, 434. [CrossRef]

(C) 2017 by the authors. Licensee MDPI, Basel, Switzerland. This article is an open access article distributed under the terms and conditions of the Creative Commons Attribution (CC BY) license (http://creativecommons.org/licenses/by/4.0/). 